\title{
A HIERARCHICAL MODEL FOR ECO-DESIGN OF CONSUMER ELECTRONIC PRODUCTS
}

\author{
Xiaojun WANG ${ }^{\mathrm{a}}$, Hing Kai CHAN ${ }^{\mathrm{b}}$, Carman K. M. LEE ${ }^{\mathrm{c}}$, Dong LI ${ }^{\mathrm{d}}$ \\ a'Department of Management, University of Bristol, Bristol, BS8 1TZ, UK \\ ${ }^{\mathrm{b}}$ Norwich Business School, University of East Anglia, Norwich, NR4 7TJ, UK \\ 'Department of Industrial \& Systems Engineering, Hong Kong Polytechnic University, \\ Hung Hom, Kowloon, Hong Kong \\ ${ }^{\mathrm{d}}$ Management School, University of Liverpool, Liverpool, L69 7ZH, UK
}

Received 6 February 2012; accepted 6 August 2012

\begin{abstract}
Designing environmentally friendly products has become a tighter requirement in the marketplace because of both the increasing trend in awareness of consumers and the obligations from legislation requirements. Unfortunately, this is not a straight forward decision for designers to evaluate whether their design options are satisfactory in terms of balancing various factors (for examples, different forms of environmental assessment) or not. This is partly attributed to the fact that there is no universally accepted approach for conducting such analysis. In this connection, this research makes reference to a European Union (EU) directive as a reference model and makes use of Analytic Hierarchical Process (AHP), which is a useful tool to help designers to make decision, for evaluating eco-design options. The AHP model is developed based on two case studies on consumer electronic products. Pairwise comparisons, one of the key steps in AHP, are conducted with the expertise gained from the case studies and the help from the software package Expert Choice. The paper also reveals how design options can be evaluated, or be screened out. The proposed method does not require the designers to conduct detailed analysis (life-cycle assessment for example) for every new product options and hence can save their time. This is particularly important when they are facing shorter and shorter product life cycle nowadays.
\end{abstract}

Keywords: AHP, eco-design, consumer electronic product, sustainability.

JEL Classification: M11, Q40.

Corresponding author Hing Kai Chan

E-mail:h.chan@uea.ac.uk 


\section{Introduction}

Design and manufacturing of environmental conscious products are of vital importance to the society as they affect the depletion of virgin materials, and consumption of natural resources (Gungor, Gupta 1999). Environmental problems such as resource depletion and air, water and land pollution have emerged as a result of intensified interventions into the environment. There is also an increasing scientific awareness of the cumulative and synergistic effects of some of the environmental impacts over space and time. For instance, some activities at the manufacturing stage may not have an immediate effect to the environment but may have a negative effect on environment during its usage or disposal when it reaches its end of life. In the interest of sustainable development, continuous improvement in the overall environmental performance of those products should be encouraged by identifying the major sources of negative environmental impacts and implementing environmentally conscious practices to minimise the impact and avoid transfer of pollution. Among these, eco-design, also known as design for environment, has been becoming an important element in new product development.

Any decisions made at the design stage could have a profound environmental impact throughout its entire product life cycle. This is reflected in the recently adopted directive by the European Council (2005) on so-called energy using products. This is later recast as the energy-related products directive (ErPs) (European Council 2009). This Directive provides for the setting of requirements which the ErPs covered by implementing measures must fulfil in order for them to be placed on the market and/or put into service in European Union. It contributes to sustainable development by increasing energy efficiency and the level of protection of the environment, while at the same time increasing the security of the energy supply. According to the ErP directive, preventive actions should be taken as early as possible during the design phase of ErPs, since it appears that the pollution caused during a product's life cycle is determined at this stage, and most of the costs involved are committed then. However, before any improvement or preventive actions are taken, environmental issues must be assessed in a holistic way, alongside technical, financial, and other criteria. Among the environmental management tools that enable to quantify the environmental burdens and assess their potential impacts, Life Cycle Assessment (LCA) (ISO 14040: 1997) is the one gaining wider acceptance in many industrial sectors.

LCA is a comprehensive technique that can be used to analyse the environmental impact of a product design. This can be reflected by numerous studies in this area (Bhander et al. 2003; Hur et al. 2005; Finnveden et al. 2009; Huntzinger, Eatmon 2009; Sobotka, Rolak 2009; Yung et al. 2011, 2012). Facing shorter product life cycle (Chiang et al. 2011), firms, however, do not normally have the leisure time to conduct LCA for each new product alternatives. Despite this restriction, developing a green design should take the whole life cycle of the product into consideration (Lin et al. 2009). Therefore, a simplified, easy to use approach is desired for quick assessment and initial screening of new product development from environmental conscious perspective, particularly from the ErP directive point of view.

This paper addresses these issues by proposing an AHP enabled novel approach to perform structured analysis of LCA. It provides a practical solution without going through the tedi- 
ous process required for conventional LCA, which can be easily adopted by businesses. One objective of LCA is to help identify options for improving the environmental performance, which is particularly important to designers and engineers, as it can inform them of how to modify a product to decrease its environmental impacts. The proposed approach will help businesses to identify key critical factors that contribute to the environmental performance throughout the product life cycle. The analysis results could be used to support the decision making process when designers or engineers consider improving the design or screening out design options in order to reduce the negative environmental impact while maintaining operational and economic efficiency.

The rest of this paper is organised as follows. The next section presents a summary of the literature in the relevant studies. For a more comprehensive review of eco-design, readers are referred to Ilgin and Gupta (2010) who summarised over 500 studies and eco-design is classified as one of the four major categories. Section 2 then presents the general hierarchical framework based on reported cases. Section 3 reveals how the proposed method can help designers screen out options with numerical examples. The final section concludes this paper.

\section{Literature review}

LCA is a quantitative environmental performance tool which provides a systematic approach to facilitate the analysis of environmental impacts. It is an effective, comprehensive and practical tool in assessing environmental impact of products by taking the life cycle characteristics of the products into consideration (Junnila 2008). LCA keeps track of the life cycle of a product from extraction of raw materials to final disposal, including manufacturing, transportation, installation, usage, and recycling. Standard LCA consists of the following components (ISO 1997): goal and scope definition, inventory analysis, impact assessment, and interpretation. A typical procedure to carry out LCA is to calculate the life cycle inventory and then interpret the results. Various indicators have been developed to help simplify the analysis (normally referred to as impact assessment) but this is also the introduction of these indicators create certain degree of inconsistency in the studies as different weightings have been applied in order to come up with final figures (like the eco-indicator). The influence of these indicators on the final results has been reported in some studies (Renou et al. 2008; Simões et al. 2011).

Since there are different pathways by which the environment can be affected, LCA considers multi-objective decision-marking in the analysis of tradeoffs between different environmental impacts (Tan 2005). The analysis will usually involve multiple objectives or criteria. Analytical Hierarchy Process (AHP) is a useful approach for evaluating complex multiple criteria alternatives (Chan et al. 2006; Chan, F. T. S., Chan, H. K. 2010; Wu et al. 2012). Since AHP was proposed by Saaty in the 1970s (Saaty 1990), it has been employed to solve Multi-Criterion Decision-Making (MCDM) problems. AHP analyses a MCDM problem by setting up a hierarchy of criteria and sub-criteria, which could be either quantitative or qualitative in nature. This can be done by introducing pairwise comparison between those criteria, which are assessed by professionals or experts in the corresponding area. Applications of AHP have been reported in many MCDM studies. Eco-design and its related topics are prevalent themes amongst studies that use AHP. For example, AHP approaches have been 
utilised to investigate issues such as assessing the environmental impacts of different stages of a supply chain life cycle (Sarkis 2003), evaluating the eco-efficiency of a product, supplier development based on environmental criteria (Lu et al. 2007), evaluating of a product's impact and influence on the environment for early product planning and development (Yang et al. 2010), and risk analysis of implementing different green initiatives (Wang et al. 2012).

One of the earlier studies to consider life cycle concept utilising a hierarchical approach was proposed by Sarkis (2003) for selecting strategic options for green supply chain management. The focus of the study, however, is put on high level green supply chain strategy rather than product design. This is also the major difference between Sarkis' study (2003) and this study. However, Sarkis (2003) illustrate the significance of employing hierarchical structure for making decision with respect to the environmental performance. Chang and Chen (2004) integrated AHP with TRIZ technique (the "theory of inventive problem solving" which is derived from its Russian origin (Fresner et al. 2010)) to evaluate the eco-efficiency of a product. Their hierarchical structure consists of seven eco-design principles (namely, material reduction, energy reduction, toxicity reduction, material retrieval, resource sustainability, product durability and product service). Although the target of their study aims at product design and the tool provided is useful, the proposed approach is applicable only at product level and overlooks other life cycle factors (like distribution, usage, etc.). Another relevant study was conducted by Kobayashi (2005) who developed a Quality Function Deployment based approach to evaluate the strategic planning for life cycle. Similar to this study, their model makes reference to LCA which is conducted beforehand. More recently, Chiang et al. (2011) developed another hierarchical model for analysing the importance of different factors for greening the electronics industries by adopting lead-free manufacturing. Notwithstanding this, and like previous studies, Chiang et al. (2011) demonstrate how the hierarchical model is applicable in assessing alternatives from the environmental performance perspective.

In the practice of eco-design, LCA provides the basic modelling framework for evaluating the environmental load and impact from its origin (i.e. raw materials) to its end-of-life. However, the conventional LCA is resource intensive and time consuming. With the high speed of technology innovation and shorter product life cycle, it is important to provide designers/engineers with a more efficient approach to assess the environmental performance of product designs. AHP has demonstrated its superiority to solve complex decision problems in wide variety of areas due to its simplicity, ease of use, and great flexibility. There is a great potential to apply LCA and AHP at product design level and enable designers to come up an environmental sound design solution within short timeframe.

Focusing on the consumer electronic product design, this paper addresses the gap in the literature by proposing a novel approach based on application of LCA and AHP. It aims to provide a practical tool that can be used to assess the environmental impact through the product life cycle and help designers evaluate or screen out design options in order or achieve sustainable new product development. Details of the model are discussed in the next section, in which the AHP model is developed based on two case studies on consumer electronic products. The model application to improve the product design is illustrated in Section 4 along with the discussion of its managerial implications. The conclusion and future directions are presented in the final section of the paper. 


\section{The AHP model}

As discussed earlier in this paper, the objective of this research is to develop an AHP model based on the LCA concept. More specifically, the ErP directive is employed as this is the main source of reference model in the field. A generic illustration is depicted in Figure 1. According to the ErP directive, a product life cycle is divided into 6 main phases, namely material (selection) phase, manufacturing phase, packaging, transportation and distribution phase, installation and maintenance phase, use phase, and end-of-life phase (European Council 2005). Since the focus of this study is on consumer electronic products, and thus the installation and maintenance phase is omitted in Figure 1. However, the same philosophy can be applied equally well to other products including this phase. The model is then divided into sub-criteria under each phase (i.e. the main criteria of the AHP model), and then each criterion and sub-criterion will affect the environmental assessment attributes that are monitored subject to the requirements of the ErP directive.

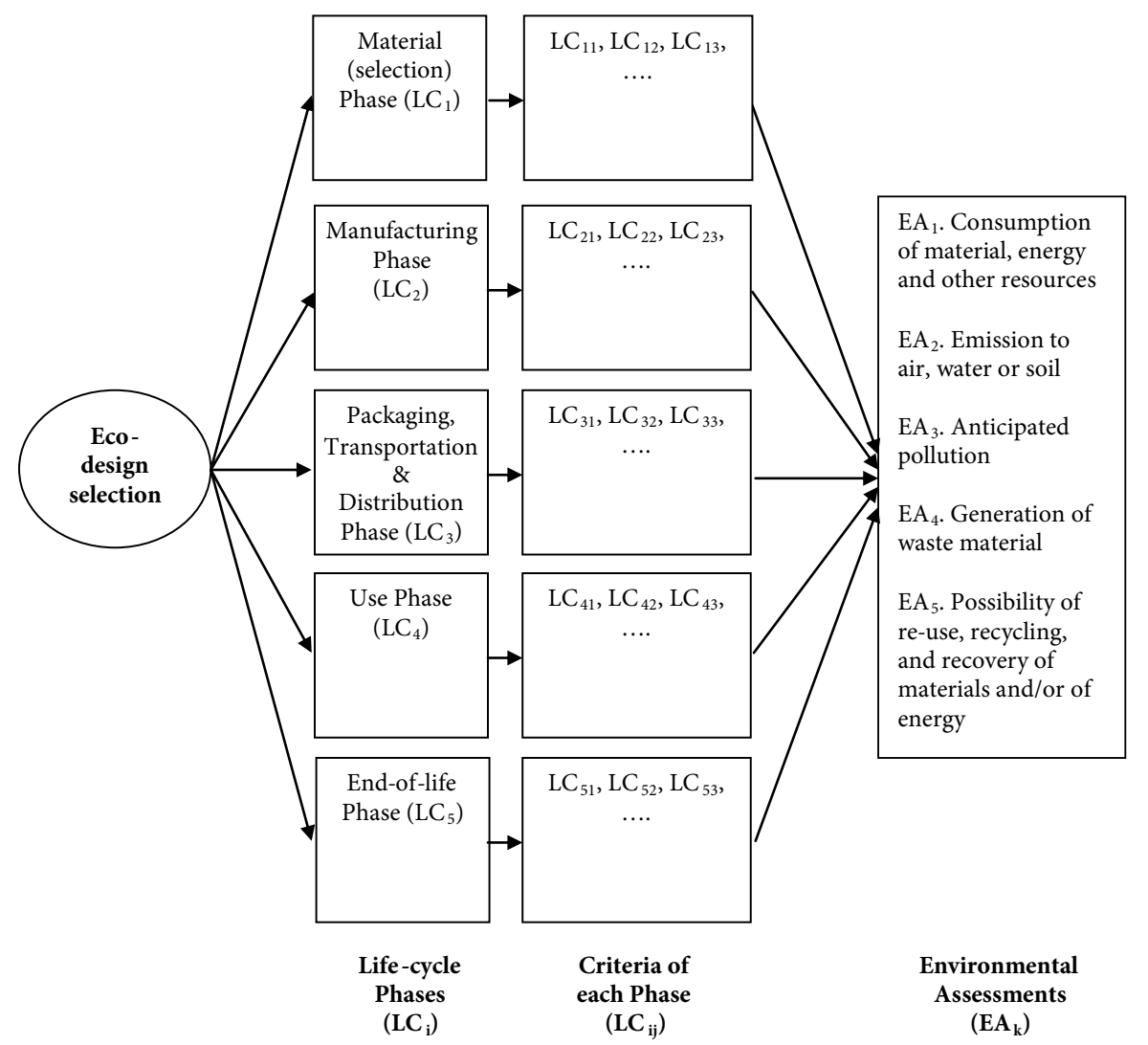

where: $i$ is the index of life-cycle phase ( $i=1$ to 5 in this case);

$j$ is the index of the criteria of each phase;

$\mathrm{k}$ is the index of the five environmental assessment attributes.

Fig. 1. Hierarchical structure for eco-design selection 
Development of the AHP model (the criteria and sub-criteria) of the case, however, is based on the case study of two electronic products described in Yung et al. $(2011,2012)$. Although the above two papers discuss two different types of product, they share a similarity: they are both consumer electronic products. In fact, the LCA results also reveal this feature. Before conducting a LCA, information has to be collected. That include bill of materials and information on the corresponding materials; the way the product is being manufactured, including what kind of machines are used; delivery methods; information on usage like electricity consumption and so on. If a part or module is purchased from the supplier, information from the supplier or a visit is needed in order to collect the material phase information. Therefore, conducting a full LCA is time consuming. This is not the intention of this paper to discuss the LCA results again and hence readers are referred to the above papers for detailed discussions in that regard. On the other hand, based on the experience of conducting the LCA by one of the authors of this paper, a generic AHP model is thus developed based on the LCA results for this type of product. This is illustrated in Figure 2.

In this model, most of the elements are grouped into categories as it is very rare that one single component would be dominating in a design, despite some distinctive items like printed circuit board (PCB) or user manual have been identified in the model. In other words, once we have a LCA as a reference, pairwise comparisons of criteria and sub-criteria to be discussed below can be assessed quite easily.

Life Cycle Phases

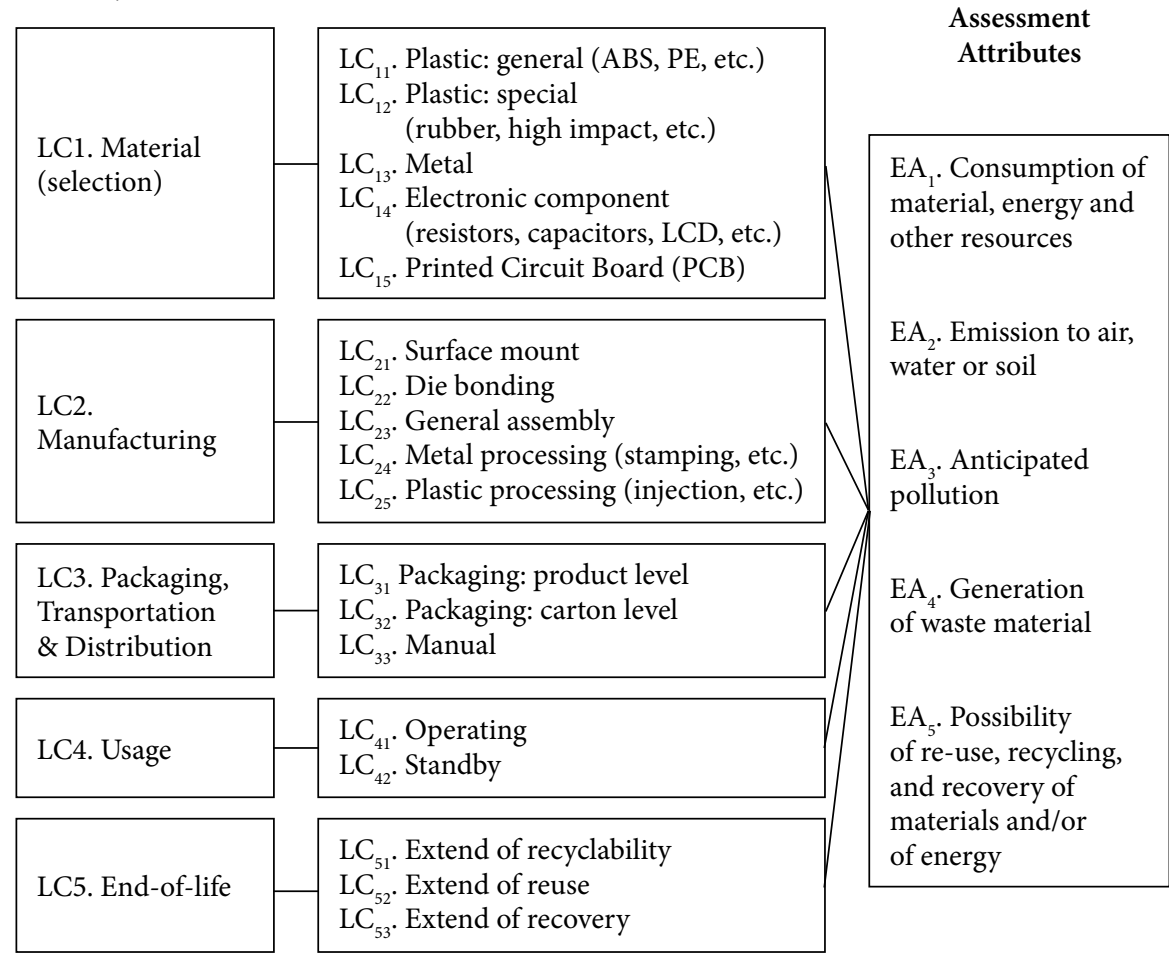

Fig. 2. The hierarchical structure for LCA-based green design selection in the case study 
In the model, material (selection) phase (i.e. the first main criterion) is dominated by five major elements: general plastics, special plastics, metal, electronic components and PCB. The first group (i.e. the first sub-criterion under this main criterion) and second group are considered separately because the extraction and production of the two types of plastics are quite different from each other and they affect the environmental assessments quite differently. The third sub-criterion groups all metal parts whereas the fourth sub-criterion considers the aggregate effect of the electronic components, which are predominately semiconductor. A similar scheme is applied to other criteria and the grouping of the respective sub-criteria, which are illustrated in Figure 2. After constructing Figure 2, the next procedure is to determine the relative importance of the criteria based on a posteriori assessment (like the LCA experience in the case studies).

The model is analysed using the software package Expert Choice, which is a commercially available package for modelling AHP (Expert Choice 1995). Pairwise comparisons, one of the key steps in AHP, are conducted with the expertise gained from the aforementioned case studies. All the inconsistency ratios have been recorded and checked to ensure that they are all below the widely recommended threshold value of 0.1 (Saaty 1987). Then, weightings for individual criterion and environmental assessment attributes are thus calculated and are listed in Table 1.

Table 1. Weighting of the AHP model (obtained from the Expert Choice software)

\begin{tabular}{|c|c|c|c|c|c|}
\hline LEVEL 1 & LEVEL 2 & LEVEL 3 & LEVEL 1 & LEVEL 2 & LEVEL 3 \\
\hline \multirow[t]{20}{*}{$\mathrm{LC}_{1}=0.512$} & \multirow[t]{5}{*}{$\mathrm{LC}_{11}=0.028$} & $\mathrm{EA}_{1}<0.001$ & \multirow[t]{15}{*}{$\mathrm{LC}_{3}=0.039$} & \multirow[t]{5}{*}{$\mathrm{LC}_{31}=0.004$} & $\mathrm{EA}_{1}=0.001$ \\
\hline & & $\mathrm{EA}_{2}=0.004$ & & & $\mathrm{EA}_{2}<0.001$ \\
\hline & & $\mathrm{EA}_{3}=0.011$ & & & $\mathrm{EA}_{3}<0.001$ \\
\hline & & $\mathrm{EA}_{4}=0.002$ & & & $\mathrm{EA}_{4}<0.001$ \\
\hline & & $\mathrm{EA}_{5}=0.010$ & & & $\mathrm{EA}_{5}=0.002$ \\
\hline & \multirow[t]{5}{*}{$\mathrm{LC}_{12}=0.150$} & $\mathrm{EA}_{1}=0.004$ & & \multirow[t]{5}{*}{$\mathrm{LC}_{32}=0.010$} & $\mathrm{EA}_{1}=0.004$ \\
\hline & & $\mathrm{EA}_{2}=0.025$ & & & $\mathrm{EA}_{2}=0.002$ \\
\hline & & $\mathrm{EA}_{3}=0.075$ & & & $\mathrm{EA}_{3}<0.001$ \\
\hline & & $\mathrm{EA}_{4}=0.013$ & & & $\mathrm{EA}_{4}<0.001$ \\
\hline & & $\mathrm{EA}_{5}=0.033$ & & & $\mathrm{EA}_{5}=0.004$ \\
\hline & \multirow[t]{5}{*}{$\mathrm{LC}_{13}=0.059$} & $\mathrm{EA}_{1}=0.015$ & & \multirow[t]{5}{*}{$\mathrm{LC}_{33}=0.025$} & $\mathrm{EA}_{1}=0.013$ \\
\hline & & $\mathrm{EA}_{2}=0.008$ & & & $\mathrm{EA}_{2}=0.004$ \\
\hline & & $\mathrm{EA}_{3}=0.004$ & & & $\mathrm{EA}_{3}=0.006$ \\
\hline & & $\mathrm{EA}_{4}=0.002$ & & & $\mathrm{EA}_{4}=0.002$ \\
\hline & & $\mathrm{EA}_{5}=0.030$ & & & $\mathrm{EA}_{5}<0.001$ \\
\hline & \multirow[t]{5}{*}{$\mathrm{LC}_{14}=0.018$} & $\mathrm{EA}_{1}=0.001$ & \multirow[t]{5}{*}{$\mathrm{LC}_{4}=0.127$} & \multirow[t]{5}{*}{$\mathrm{LC}_{41}=0.111$} & $\mathrm{EA}_{1}=0.070$ \\
\hline & & $\mathrm{EA}_{2}=0.005$ & & & $\mathrm{EA}_{2}=0.015$ \\
\hline & & $\mathrm{EA}_{3}=0.003$ & & & $\mathrm{EA}_{3}=0.015$ \\
\hline & & $\mathrm{EA}_{4}=0.008$ & & & $\mathrm{EA}_{4}=0.006$ \\
\hline & & $\mathrm{EA}_{5}<0.001$ & & & $\mathrm{EA}_{5}=0.004$ \\
\hline
\end{tabular}


Continued Table 1

\begin{tabular}{|c|c|c|c|c|c|}
\hline LEVEL 1 & LEVEL 2 & LEVEL 3 & LEVEL 1 & LEVEL 2 & LEVEL 3 \\
\hline & \multirow[t]{5}{*}{$\mathrm{LC}_{15}=0.257$} & $\mathrm{EA}_{1}=0.014$ & & \multirow[t]{5}{*}{$\mathrm{LC}_{42}=0.016$} & $\mathrm{EA}_{1}=0.010$ \\
\hline & & $\mathrm{EA}_{2}=0.028$ & & & $\mathrm{EA}_{2}=0.002$ \\
\hline & & $\mathrm{EA}_{3}=0.055$ & & & $\mathrm{EA}_{3}=0.002$ \\
\hline & & $\mathrm{EA}_{4}=0.152$ & & & $\mathrm{EA}_{4}<0.001$ \\
\hline & & $\mathrm{EA}_{5}=0.008$ & & & $\mathrm{EA}_{5}<0.001$ \\
\hline \multirow[t]{25}{*}{$\mathrm{LC}_{2}=0.293$} & \multirow[t]{5}{*}{$\mathrm{LC}_{21}=0.013$} & $\mathrm{EA}_{1}=0.007$ & \multirow[t]{25}{*}{$\mathrm{LC}_{5}=0.029$} & \multirow[t]{5}{*}{$\mathrm{LC}_{51}=0.003$} & $\mathrm{EA}_{1}=0.001$ \\
\hline & & $\mathrm{EA}_{2}=0.001$ & & & $\mathrm{EA}_{2}<0.001$ \\
\hline & & $\mathrm{EA}_{3}=0.001$ & & & $\mathrm{EA}_{3}<0.001$ \\
\hline & & $\mathrm{EA}_{4}=0.004$ & & & $\mathrm{EA}_{4}<0.001$ \\
\hline & & $\mathrm{EA}_{5}<0.001$ & & & $\mathrm{EA}_{5}=0.001$ \\
\hline & \multirow[t]{5}{*}{$\mathrm{LC}_{22}=0.009$} & $\mathrm{EA}_{1}=0.005$ & & \multirow[t]{5}{*}{$\mathrm{LC}_{52}=0.018$} & $\mathrm{EA}_{1}=0.008$ \\
\hline & & $\mathrm{EA}_{2}<0.001$ & & & $\mathrm{EA}_{2}=0.002$ \\
\hline & & $\mathrm{EA}_{3}<0.001$ & & & $\mathrm{EA}_{3}=0.002$ \\
\hline & & $\mathrm{EA}_{4}=0.002$ & & & $\mathrm{EA}_{4}<0.001$ \\
\hline & & $\mathrm{EA}_{5}<0.001$ & & & $\mathrm{EA}_{5}=0.007$ \\
\hline & \multirow[t]{5}{*}{$\mathrm{LC}_{23}=0.036$} & $\mathrm{EA}_{1}=0.003$ & & \multirow[t]{5}{*}{$\mathrm{LC}_{53}=0.007$} & $\mathrm{EA}_{1}=0.003$ \\
\hline & & $\mathrm{EA}_{2}=0.014$ & & & $\mathrm{EA}_{2}<0.001$ \\
\hline & & $\mathrm{EA}_{3}=0.014$ & & & $\mathrm{EA}_{3}<0.001$ \\
\hline & & $\mathrm{EA}_{4}=0.004$ & & & $\mathrm{EA}_{4}<0.001$ \\
\hline & & $\mathrm{EA}_{5}=0.001$ & & & $\mathrm{EA}_{5}=0.003$ \\
\hline & \multirow[t]{5}{*}{$\mathrm{LC}_{24}=0.067$} & $\mathrm{EA}_{1}=0.037$ & & & \\
\hline & & $\mathrm{EA}_{2}=0.005$ & & & \\
\hline & & $\mathrm{EA}_{3}=0.005$ & & & \\
\hline & & $\mathrm{EA}_{4}=0.013$ & & & \\
\hline & & $\mathrm{EA}_{5}=0.006$ & & & \\
\hline & \multirow[t]{5}{*}{$\mathrm{LC}_{25}=0.168$} & $\mathrm{EA}_{1}=0.083$ & & & \\
\hline & & $\mathrm{EA}_{2}=0.014$ & & & \\
\hline & & $\mathrm{EA}_{3}=0.014$ & & & \\
\hline & & $\mathrm{EA}_{4}=0.038$ & & & \\
\hline & & $\mathrm{EA}_{5}=0.019$ & & & \\
\hline
\end{tabular}

In addition to that, Figure 3 and Figure 4 summarise the overall weightings of different life-cycle phases and environmental assessments respectively. These figures not only serve to exemplify the results but act as a validation method to verify that the output of the proposed model is in line with the results from the LCA results obtained by Yung et al. $(2011,2012)$ in a broader sense.

Refer to Table 1 and Figure 3, it can be concluded that $\mathrm{LC}_{1}$ (the material selection phase) contributes most to the environmental assessments followed by $\mathrm{LC}_{2}$ (the manufacturing phase). To probe further, $\mathrm{LC}_{15}$ (PCB) and $\mathrm{LC}_{12}$ (special types of plastic) are the two most important criteria under $\mathrm{LC}_{1}$. The former contributes more than $50 \%$ of that phase $\left(\mathrm{LC}_{1}\right)$, 


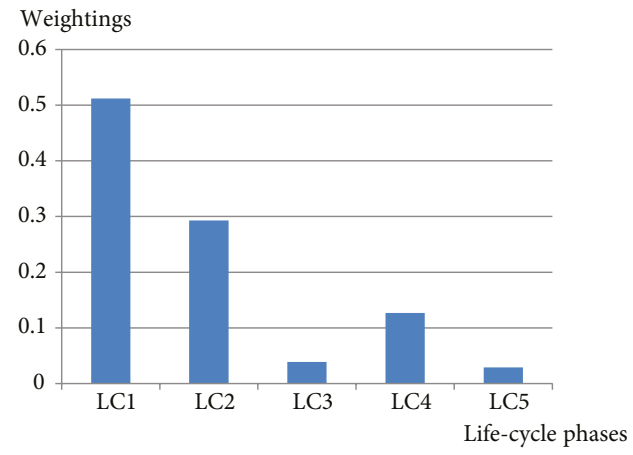

Fig. 3. Overall weightings of different life-cycle phases

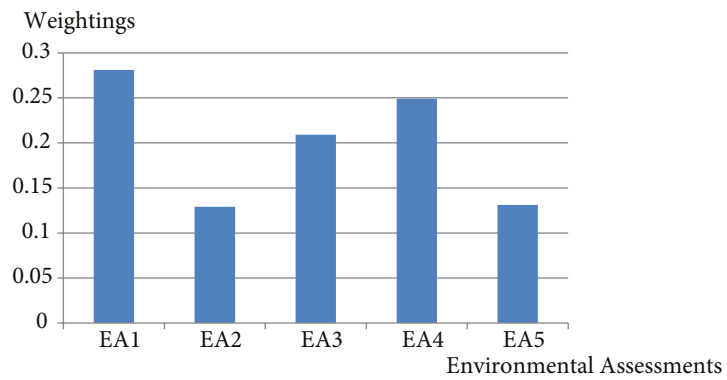

Fig. 4. Overall weightings of different environmental assessments

whereas the second one contributes almost $30 \%$ of that phase. Another important life-cycle phase is $\mathrm{LC}_{2}$ (the manufacturing phase). Among the criteria under this phase, $\mathrm{LC}_{25}$ (plastic processing) and $\mathrm{LC}_{24}$ (metal processing) ranked at the top which contributes over $50 \%$ and $20 \%$ of the environmental assessments respectively. Apart from the above, other phases should not be overlooked, of course. It is very obvious that $\mathrm{LC}_{33}$ (manual), $\mathrm{LC}_{41}$ (operating), and $\mathrm{LC}_{52}$ (extend of reuse) are the core factors of their respective life cycle phase (all over $50 \%$ with respect to their life-cycle phase).

These results are in fact all in line with the studies of Yung et al. $(2011,2012)$. In other words, improvement options should be proposed pinpointing these phases and the corresponding criteria. The most straightforward design options are then to reduce the size of PCB and usage of special types of plastic should be reduced, which can also help to reduce the impact created by plastic processing. In addition, size of user manual (for example, changing from a multi-language manual to a single-language manual or a graphic, which is also a kind of commonly known language, dominated manual), and usage of electricity in the operating mode should also be taken into consideration. The former in fact affects the packaging design and hence also contribute to the environmental impacts generated in the packaging, transportation \& distribution phase as the larger the packaging, the bigger the volume of the overall product size. For the latter, it is also a matter of environmental consciousness: whether the software and hardware designers have taken this into consideration or not. 
The next question, however, is that, how to evaluate a new design (with different options on different criteria) without going through the LCA. This is also the rationale of conducting this research; otherwise, there is no need to construct the AHP and to determine the above weightings. Next section will demonstrate that how designers can evaluate design options based on the AHP model and the associated weightings (obtained from a LCA of a similar product type).

\section{Screening new options: scenarios analysis and managerial implications}

Since the outputs of the LCA (or environmental assessments to be precise) are dependent on all the criteria, which means each individual criterion contributes to each environmental assessment differently as illustrated in the complexity of the AHP model. In other words, if one changes the design from environmental point of view, it is not easy to access the effects of the combination of different possible options. Conducting LCA for each individual combination is fine but time required is unaffordable (like Yung et al. $(2011,2012)$ ). This is also the reason why we propose to construct an AHP based on one LCA and then design options can be screened out quickly. This is possible based on the fact that the overall $\mathrm{EA}_{\mathrm{k}}$ values $(\mathrm{k}=1$ to 5$)$, the five environmental assessments as illustrated in Figure 1, in the AHP model is in fact a sum of all $\mathrm{EA}_{\mathrm{k}}\left(\mathrm{LC}_{\mathrm{ij}}\right)$, which is the $\mathrm{EA}_{\mathrm{k}}$ value of each criterion $\mathrm{LC}_{\mathrm{ij}}$. For example, $\mathrm{EA}_{1}\left(\mathrm{LC}_{13}\right)=0.015$ as in Table 1. Mathematically, this can be expressed by Eq. (1):

$$
\mathrm{EA}_{\mathrm{k}}=\sum_{\mathrm{i}} \sum_{\mathrm{j}} \mathrm{EA}_{\mathrm{k}}\left(\mathrm{LC}_{\mathrm{ij}}\right) \text {. }
$$

Therefore, $\mathrm{EA}_{1}=0.0005+0.004+0.015+\ldots+0.003=0.2795$, which is also shown in Figure 4. In this connection, a small disturbance $\mathrm{DLC}_{\mathrm{ij}}$ (i.e. design change) on $\mathrm{LC}_{\mathrm{ij}}$ will introduce deviation of the corresponding EA values. Basic calculus allows us to find an approximate of the new $\mathrm{EA}_{\mathrm{k}}^{\prime}$ values that can be estimated as by Eq. (2):

$$
\mathrm{EA}_{\mathrm{k}}^{\prime}=\sum_{\mathrm{i}} \sum_{\mathrm{j}}\left(\mathrm{EA}_{\mathrm{k}}\left(\mathrm{LC}_{\mathrm{ij}}\right)+\Delta \mathrm{LC}_{\mathrm{ij}} \frac{\partial \mathrm{EA}_{\mathrm{k}}\left(\mathrm{LC}_{\mathrm{ij}}\right)}{\partial \mathrm{LC}_{\mathrm{ij}}}\right) .
$$

Since each EA value has a linear relationship to each $\mathrm{LC}_{\mathrm{ij}}$ in this case (which is either dependent on the weight or volume of the input parameter), new $\mathrm{EA}_{\mathrm{k}}^{\prime}$ values can thus be estimated very easily. This can be shown by the following example.

Employing the case discussed in Section 2, $\mathrm{LC}_{12}$ and $\mathrm{LC}_{15}$ have been identified as improvement options because of their high contribution to the EA values. Assume that we can radically change the PCB size by a reduction of $20 \%$ (New Design 1 ), or reduction in the usage of special plastic by $20 \%$ (New Design 2), but not both due to technical limitation. However, the designer can accept a compromise that both changes are limited to $10 \%$ (New Design 3 ). The percentage improvement on each EA value is thus estimated and summarised in Table 2 using the equations above. For example, $\mathrm{EA}_{1}$ for the New Design 1 under this simple example would be equal to $\mathrm{EA}_{1}+\mathrm{EA}_{1}\left(\mathrm{LC}_{15}\right) \times \mathrm{DLC}_{15}=0.2795+0.014 \times(-0.2)=0.2767$, which gives the percentage improvement value of $\mathrm{EA}_{1}$ in Table 2. Similar calculations can be applied to other new EA values and hence other percentage improvement values in Table 2, so the numerical examples are skipped here. 
Table 2. Percentage improvement of the EA values on three new designs

\begin{tabular}{cccc}
\hline & New Design 1 & New Design 2 & New Design 3 \\
\hline EA $_{1}$ & -1.00 & -0.29 & -0.64 \\
\hline EA $_{2}$ & -4.27 & -3.82 & -4.05 \\
\hline EA $_{3}$ & -5.25 & -7.16 & -6.21 \\
\hline EA $_{4}$ & -12.21 & -1.04 & -6.63 \\
\hline EA $_{5}$ & -1.23 & -5.06 & -3.14 \\
\hline
\end{tabular}

Note:

- New Design 1: $\mathrm{LC}_{15}$ reduced by $20 \%$;

- New Design 2: $\mathrm{LC}_{12}$ reduced by $20 \%$;

- New Design 3: $\mathrm{LC}_{12}$ and $\mathrm{LC}_{15}$ reduced by $10 \%$;

- The more negative the values, the better the percentage improvement compared to the original design.

From Table 2, it can easily be seen that if we compare New Design 1 and New Design 2, the former can further reduce (i.e. optimise) the $\mathrm{EA}_{4}$ value but the latter performs better in $\mathrm{EA}_{5}$ in a relative sense. Unfortunately, they cannot be taken on board at the same time. Nevertheless, the compromise, New Design 3 can achieve a relatively good result on various EA values. Of course, each of which is not the best compared to New Design 1 and New Design 2. This is further demonstrated in the radar diagram as shown in Figure 5, which can be used as the eco-profile as outlined in the ErP directive. In other words, this can not only be used for evaluating new design options, but be used to fulfil the legislative requirements. This analysis cannot be documented without this tool, or conducting LCA for each design. This is also one of the requirements in the ErP directive that the manufacturer needs to consider in the design stage.

Above example is a simple illustration but it is good enough to demonstrate how a combination of design options can be decided (or compromised). This is exactly the major contribution of this research. If a designer wants to evaluate the environmental impacts of all possible combinations using LCA, the time needed would be quite impractical. However, the proposed method only needs an initial LCA data from a similar product, and

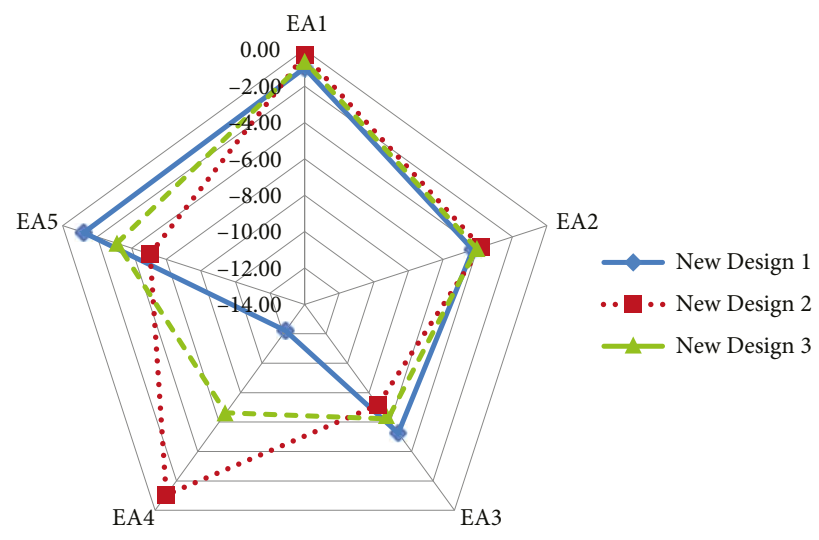

Fig. 5. Comparison of different designs (in terms of percentage improvement) 
then setup an Excel spreadsheet to come up with the above estimation. Although above example illustrates the concept using two factors $\mathrm{LC}_{12}$ and $\mathrm{LC}_{15}$ only (they are the most problematic criteria under $\mathrm{LC}_{1}$, which is the most critical life-cycle phase in the case), above method is capable to be used to consider different combination generated from different criteria. In addition, the above model can also cater the situation that altering one criterion (reduction in the total weight of plastic used, for example) may create opposite effects from other factors (increase in the usage of metal to strengthen the support of the body, for example). The focus of such analysis is thus put on the overall effect of the final EA values. Interpretation of the eco-profile like Figure 5 also avoids the use of, for example, eco-indicator as discussed earlier.

To further demonstrate the usefulness of the proposed approach by a complete new design, the proposed design suggested by Yung et al. (2011) is employed to go through the whole process. Various design options have been suggested in Yung et al. (2011) and the final design is summarised in Table 3, with a rough estimation of the percentage change (i.e. improvement) of each item in the last column. This incorporates all the feasible design options together. Using the method outline above, the estimated percentage improvement on each environmental attribute is portrayed in Figure 6. As mentioned before, this eco-profile can be documented as a source of evidence that various attributes can be improved by introducing the new design options. More importantly, it gives a fast access to the whole picture of the impact of the new design.

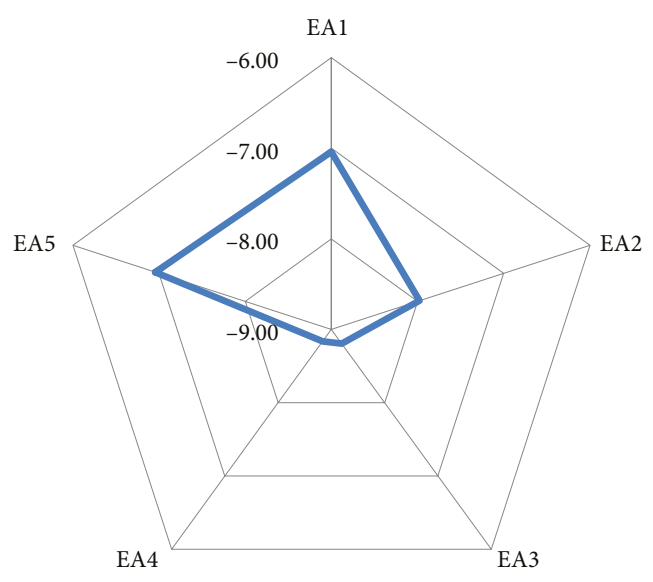

Fig. 6. Percentage improvement of the new design

The proposed model can not only help designer to prioritise alternatives, but to conduct similar LCA easier for selecting new design options. Obviously, the proposed model is not aimed to replace LCA or undermined the usefulness of LCA, as a full LCA should still be conducted for the, say, final two options. The major objective of developing the model is to provide a "shortcut" to designers to screen out less feasible solutions. 
Table 3. A summary of the redesign options based on Yung et al. (2011)

\begin{tabular}{|c|c|c|c|}
\hline $\begin{array}{l}\text { Life Cycle } \\
\text { Phases }\end{array}$ & Criteria & Improvement (Yung et al. 2011) & $\begin{array}{l}\text { Rough } \\
\text { percentage of } \\
\text { improvement }\end{array}$ \\
\hline \multirow{5}{*}{$\begin{array}{l}\mathrm{LC}_{1} \cdot \text { Material } \\
\text { (selection) }\end{array}$} & $\begin{array}{l}\mathrm{LC}_{11} \cdot \\
\text { Plastic: general } \\
\text { (ABS, PE, etc.) }\end{array}$ & $\begin{array}{l}\text { Reduce the thickness of part of the casing; } \\
\text { Redesign the user interface so that less } \\
\text { switches are needed }\end{array}$ & $5 \%$ \\
\hline & $\begin{array}{l}\mathrm{LC}_{12} \\
\text { Plastic: special (rubber, } \\
\text { high impact, etc.) }\end{array}$ & $\begin{array}{l}\text { Combine the housing } \\
\text { (with general plastics) with the lens } \\
\text { (with special plastic) }\end{array}$ & $10 \%$ \\
\hline & $\mathrm{LC}_{13} \cdot$ Metal & $\begin{array}{l}\text { Redesign the housing so that clips are } \\
\text { used instead of screw }\end{array}$ & $5 \%$ \\
\hline & $\begin{array}{l}\mathrm{LC}_{14} \text {. Electronic } \\
\text { component (resistors, } \\
\text { capacitors, LCD, etc.) }\end{array}$ & $\begin{array}{l}\text { Remove the radio-controlled clock } \\
\text { and size of LCD }\end{array}$ & $5 \%$ \\
\hline & $\begin{array}{l}\mathrm{LC}_{15^{\circ}} \\
\text { Printed Circuit Board } \\
(\mathrm{PCB})\end{array}$ & $\begin{array}{l}\text { Reduce the size by integrating some small } \\
\text { PCBs into the main PCB; } \\
\text { Remove the radio-controlled clock }\end{array}$ & $10 \%$ \\
\hline \multirow{5}{*}{$\begin{array}{l}\mathrm{LC}_{2} \text {. } \\
\text { Manufacturing }\end{array}$} & $\mathrm{LC}_{21}$. Surface mount & Not specified & Not specified \\
\hline & $\mathrm{LC}_{22}$. Die bonding & Not specified & Not specified \\
\hline & $\mathrm{LC}_{23}$. General assembly & $\begin{array}{l}\text { Redesign the housing so that clips } \\
\text { are used instead of screw }\end{array}$ & $5 \%$ \\
\hline & $\begin{array}{l}\mathrm{LC}_{24} \text {. Metal processing } \\
\text { (stamping, etc.) }\end{array}$ & Not specified & Not specified \\
\hline & $\begin{array}{l}\mathrm{LC}_{25} \text {. Plastic processing } \\
\text { (injection, etc.) }\end{array}$ & $\begin{array}{l}\text { Reduce the thickness of part of the casing; } \\
\text { Less switches are needed }\end{array}$ & $10 \%$ \\
\hline \multirow{3}{*}{$\begin{array}{l}\text { LC }_{3} \text {. Packaging, } \\
\text { Transportation } \\
\text { \& Distribution }\end{array}$} & $\begin{array}{l}\mathrm{LC}_{31} \text { Packaging: } \\
\text { product level }\end{array}$ & Use paper instead of blister & $10 \%$ \\
\hline & $\begin{array}{l}\mathrm{LC}_{32} \text {. Packaging: } \\
\text { carton level }\end{array}$ & $\begin{array}{l}\text { Packing density is increased by making } \\
\text { the packing more regular in shape } \\
\text { (a matter of re-configure the placement } \\
\text { of different devices) }\end{array}$ & $10 \%$ \\
\hline & $\mathrm{LC}_{33}$. Manual & $\begin{array}{l}\text { Redesign the manual so that single- } \\
\text { language manual is used instead } \\
\text { of multi-language manual }\end{array}$ & $20 \%$ \\
\hline \multirow[b]{2}{*}{$\mathrm{LC}_{4}$. Usage } & $\mathrm{LC}_{41}$. Operating & Remove the radio-controlled clock & $5 \%$ \\
\hline & $\mathrm{LC}_{42} \cdot$ Standby & $\begin{array}{l}\text { The device only triggered for wake up } \\
\text { by events, rather than regular as in the } \\
\text { existing solution }\end{array}$ & $20 \%$ \\
\hline \multirow{3}{*}{ LC $_{5}$. End-of-life } & $\begin{array}{l}\mathrm{LC}_{51} \text {. Extend } \\
\text { of recyclability }\end{array}$ & Not specified & Not specified \\
\hline & $\mathrm{LC}_{52}$. Extend of reuse & & \\
\hline & $\mathrm{LC}_{53}$. Extend of recovery & & \\
\hline
\end{tabular}




\section{Conclusions}

Eco-design is increasingly important for designers to consider during new product development. Prioritizing design alternatives becomes more applicable in the case that a comprehensive environmental impact assessment may not be easy to conduct while the product development is often tight. This research proposes an effective and systematic decision support approach to help designers to evaluate and select new design options. It highlights key critical factors that contribute to the environmental performance throughout the product life cycle and help the designers to analyse design options in order to lessen negative environmental impact while maintaining operational and economic efficiency. Compared to conventional LCA, the AHP approach proposed in this paper provide a practical LCA solution, which is simple, being less demanding with respect to the computational power and time needed to make a decision. Designers do not need to go through full LCA for each design option in order to come up with a speedier screening decision. In addition, most numerical calculations can be computed using Microsoft Excel, despite the numerical analysis is conducted with the help of commercially available software package Expert Choice. Therefore, the proposed approach does not require proprietary LCA software for analysis and the time required to complete this analysis is definitely affordable. In spite of the above, it is not the intention of the authors to assert that the proposed method can replace LCA, which remains a scientifically robust tool for analysing the environmental impacts of a design. However, the proposed approach can definitely supplement full LCA for screening purpose practically.

Despite the various advantages of the proposed approach for practical LCA outlined in the paper, there are some limitations which can lead to further research opportunities. For instances, the AHP model is developed based on two case studies on consumer electronic products. This research work can be easily extended to analyse other product families. In addition, although AHP is a useful method for MCDM problems, it has difficulty to deal with uncertain parameters which could present in the process because of the uncertainty nature of the problem or lack of environmental data. In many cases, uncertainty problems cannot be expressed simply by using crisp values (e.g. Chan et al. 2003; Wang et al. 2012). One research direction is using fuzzy set theory to deal with uncertain parameters to support decision making in order to overcome this shortcoming of AHP (Amiri 2010; Buyukozkan et al. 2011).

Furthermore, the numerical analysis shows the dynamic nature of problem when evaluating alternative design options. Yet, for the case of eco-design, the design decision will broadly affect the environmental performance of not just one, but other assessment attributes throughout its product life cycle. For example, "Material Selection" phase may have an impact in other phases such as "Manufacturing" or "Usage". The dynamic nature of a product life cycle means that the decision model for evaluating eco-designs should reflect the interaction and relationships among the life cycle phases and associated criteria. The dynamic characteristics and complexity of this decision environment would require intensive and robust analysis in the decision making process. To accomplish this goal, one possible future research direction is to use the analytic network process (ANP) to incorporate critical factors and their interdependences in the consideration (Saaty 2004). 


\section{References}

Amiri, M. P. 2010. Project selection for oil-fields development by using the AHP and fuzzy TOPSIS methods, Expert Systems with Applications 37(9): 6218-6224. http://dx.doi.org/10.1016/j.eswa.2010.02.103

Bhander, G. S.; Hauschild, M.; McAloone, T. 2003. Implementing life cycle assessment in product development, Environmental Progress 22(4): 255-267. http://dx.doi.org/10.1002/ep.670220414

Buyukozkan, G.; Cifci, G.; Guleryuz, S. 2011. Strategic analysis of healthcare service quality using fuzzy AHP methodology, Expert Systems with Applications 38(8): 9407-9424.

http://dx.doi.org/10.1016/j.eswa.2011.01.103

Chan, F. T. S.; Chan, H. K. 2010. An AHP model for selection of suppliers in the fast changing fashion market, International Journal of Advanced Manufacturing Technology 51(9-12): 1195-1207. http://dx.doi.org/10.1007/s00170-010-2683-6

Chan, F. T. S.; Chan, H. K.; Kazerooni, A. 2003. Real time fuzzy scheduling rules in FMS, Journal of Intelligent Manufacturing 14(3-4): 341-350. http://dx.doi.org/10.1023/A:1024601826420

Chan, F. T. S.; Chan, H. K.; Lau, H. C. W.; Ip, R. W. L. 2006. Benchmarking logistics performance of the postal industry - a double AHP approach, Benchmarking: An International Journal 13(6): 636-661.

Chang, H.-T.; Chen, J. L. 2004. The conflict-problem-solving CAD software integrating TRIZ into eco-innovation, Advances in Engineering Software 35(8-9): 553-566. http://dx.doi.org/10.1016/j.advengsoft.2004.06.003

Chiang, S.-Y.; Wei, C.-C.; Chiang, T.-H.; Chen, W.-L. 2011. How can electronics industries become green manufacturers in Taiwan and Japan, Clean Technologies and Environmental Policy 13(1): 37-47. http://dx.doi.org/10.1007/s10098-010-0284-6

European Council 2005. Directive 2005/32/EC of the European Parliament of the council of 6 July 2005 establishing a framework for the settings of ecodesign requirements for energy-using products and amending Council Directive 92/42/EEC and Directive 96/57/EC and 2000/55/EC of the European Parliament and of the Council, Official Journal of the European Union L191/58: 29-58.

European Council 2009. Directive 2009/125/EC of the European Parliament and of the council of 21 October 2009 establishing a framework for the settings of ecodesign requirements for energy-related products (recast), Official Journal of the European Union L285: 10-35.

Expert Choice 1995. Decision support software. Expert Choice Inc. $121 \mathrm{p}$.

Finnveden, G.; Hauschild, M. Z.; Ekvall, T.; Guinee, J.; Heijungs, R.; Hellweg, S.; Koehler, A.; Pennington, D.; Suh, S. 2009. Recent developments in Life Cycle Assessment, Journal of Environmental Management 91(1): 1-21. http://dx.doi.org/10.1016/j.jenvman.2009.06.018

Fresner, J.; Jantschgi, J.; Birkel, S.; Barnthaler, J.; Krenn, C. 2010. The theory of inventive problem solving (TRIZ) as option generation tool within cleaner production projects, Journal of Cleaner Production 18(2): 128-136. http://dx.doi.org/10.1016/j.jclepro.2009.08.012

Gungor, A.; Gupta, S. M. 1999. Issues in environmentally conscious manufacturing and product recovery: a survey, Computers \& Industrial Engineering 36(4): 811-853. http://dx.doi.org/10.1016/S0360-8352(99)00167-9

Huntzinger, D. N.; Eatmon, T. D. 2009. A life-cycle assessment of Portland cement manufacturing: comparing the traditional process with alternative technologies, Journal of Cleaner Production 17(7): 668-675. http://dx.doi.org/10.1016/j.jclepro.2008.04.007

Hur, T.; Lee, J.; Ryu, J.; Kwon, E. 2005. Simplified LCA and Matrix methods in indentifying the environmental aspects of a product system, Journal of Environmental Management 75(3): 229-237. http://dx.doi.org/10.1016/j.jenvman.2004.11.014

Ilgin, M. A.; Gupta, S. M. 2010. Environmentally conscious manufacturing and product recovery (ECMPRO): a review of the state of the art, Journal of Environmental Management 91(3): 563-591. http://dx.doi.org/10.1016/j.jenvman.2009.09.037 
ISO 14040: 1997. Environmental Management. Life Cycle Assessment: Principles and Framework. International Organisation for Standardisation.

Junnila, S. 2008. Life cycle management of energy-consuming products in companies using IO-LCA, International Journal of Life Cycle Assessment 13(5): 432-439. http://dx.doi.org/10.1007/s11367-008-0015-y

Kobayashi, H. 2005. Strategic evolution of eco-products: a product life cycle planning methodology, Research in Engineering Design 16(1-2): 1-16. http://dx.doi.org/10.1007/s00163-005-0001-3

Lin, S.-S.; Juang, Y.-S.; Chen, M.-Y.; Yu, C.-J. 2009. Analysis of green design criteria and alternative evaluation processes for 3C products, in Proc. of the Asia Pacific Industrial Engineering \& Management Systems Conference (APIEMS 2009), 14-16 December 2009, Kitakyushu, Japan, 2675-2685.

Lu, L. Y. Y.; Wu, C. H.; Kuo, T.-C. 2007. Environmental principles applicable to green supplier evaluation by using multi-objective decision analysis, International Journal of Production Research 45(18-19): 4317-4331. http://dx.doi.org/10.1080/00207540701472694

Renou, S.; Thomas, J. S.; Aoustin, E.; Pons, M. N. 2008. Influence of impact assessment methods in wastewater treatment LCA, Journal of Cleaner Production 16(10): 1098-1105. http://dx.doi.org/10.1016/j.jclepro.2007.06.003

Saaty, R. W. 1987. The analytic hierarchy process - what it is and how it is used, Mathematical Modelling 9(3-5): 161-176. http://dx.doi.org/10.1016/0270-0255(87)90473-8

Saaty, T. L. 1990. How to make a decision: the analytic hierarchical process, European Journal of Operational Research 48(1): 9-26. http://dx.doi.org/10.1016/0377-2217(90)90057-I

Saaty, T. L. 2004. Fundamentals of the analytic network process - dependence and feedback in decision-making with a single network, Journal of Systems Science and Systems Engineering 13(2): 129-157. http://dx.doi.org/10.1007/s11518-006-0158-y

Sarkis, J. 2003. A strategic decision framework for green supply chain management, Journal of Cleaner Production 11(4): 397-409. http://dx.doi.org/10.1016/S0959-6526(02)00062-8

Simões, C. L.; Xará, S. M.; Bernardo, C. A. A. 2011. Influence of the impact assessment method on the conclusions of a LCA study. Application to the case of a part made with virgin and recycled HDPE, Waste Management \& Research 29(10): 1018-1026. http://dx.doi.org/10.1177/0734242X11403799

Sobotka, A.; Rolak, Z. 2009 Multi-attribute analysis for the eco-energetic assessment of the building life cycle, Technological and Economic Development of Economy 15(4): 593-611. http://dx.doi.org/10.3846/1392-8619.2009.15.593-611

Tan, R. R. 2005. Rule-based life cycle impact assessment using modified rough set induction methodology, Environmental Modelling \& Software 20(5): 509-513. http://dx.doi.org/10.1016/j.envsoft.2004.08.005

Wang, X.; Chan, H. K.; Yee, W. Y.; Diaz-Rainey, I. 2012. A two-stage fuzzy-AHP model for risk assessment of implementing green initiatives in the fashion supply chain, International Journal of Production Economics 135(2): 595-606. http://dx.doi.org/10.1016/j.ijpe.2011.03.021

Wu, W.; Kou, G.; Peng, Y.; Ergu, D. 2012. Improved AHP-group decision making for investment strategy selection, Technological and Economic Development of Economy 18(2): 299-316.

http://dx.doi.org/10.3846/20294913.2012.680520

Yang, C.; Liu, T.; Kao, C.; Wang, H. 2010. Integrating AHP and DELPHI methods to construct a green product assessment hierarchy for early stage of product design and development, International Journal of Operations Research 7(3): 35-43.

Yung, W. K. C.; Chan, H. K.; So, J. H. T.; Wong, D. W. C.; Choi, A. C. K.; Yue, T. M. 2011. A life-cycle assessment for eco-redesign of a consumer electronic product: a case study, Journal of Engineering Design 22(2): 69-85. http://dx.doi.org/10.1080/09544820902916597

Yung, W. K. C.; Chan, H. K.; Wong, D. W. C.; So, J. H. T.; Choi, A. C. K.; Yue, T. M. 2012. Eco-redesign of a personal electronic product subject to the energy-using product directive, International Journal of Production Research 50(5): 1411-1423. http://dx.doi.org/10.1080/00207543.2011.571941 
Xiaojun WANG. Doctor, Senior Lecturer at the School of Economics, Finance and Management, University of Bristol. He has published in Journals such as OMEGA: International Journal of Management Science, International Journal of Production Research, IEEE Transactions on Engineering Management, and several others. His current research interests include operations and supply chain management, sustainable development, multi-criteria decision analysis, and applied operational research.

Hing Kai CHAN. Doctor, Senior Lecturer in the Norwich Business School, University of East Anglia. He has published in Journals such as International Journal of Production Research, International of Production Research, Decision Support Systems, and various IEEE Transactions, among others. His current research interests include sustainable supply chain, supply chain modelling and simulation, advanced industrial or manufacturing systems, and applications of soft computing on intelligent industrial systems and supply chains.

Carman K. M. LEE. Doctor, is an Assistant Professor in the Department of Industrial and Systems Engineering, The Hong Kong Polytechnic University. She obtained her PhD and B Eng degree from The Hong Kong Polytechnic University. She was awarded Bronze Award of 16th China National Invention Exhibition Award in 2006 and Outstanding Professional Service and Innovation Award, The Hong Kong Polytechnic University in 2006. She has (co-)authored more than 100 journal and conferences papers. Her current research areas include logistics information management, manufacturing information systems, product development and data mining techniques.

Dong LI. Reader in Operations and Supply Chains Management, Management School, University of Liverpool. He is the grants holder for research projects funded by UK EPSRC and TSB, EU FP7 and ERDF in the above areas. His research has been published extensively in peer reviewed international journals. His present research has been mainly in the areas of food supply chain innovation, green logistic and sustainable supply chain management. 